\title{
Iranian English Language Learners' Attitude towards their Accent in English Language: An Ecological Approach
}

\author{
Farzaneh Rajablou \\ farzanehrajablou@gmail.com \\ Imam Reza International University, Iran
}

\author{
Majid Elahi Shirvan \\ elahimajid64@gmail.com \\ University of Bojnord, Iran
}

\begin{abstract}
With the spread of English around the world and the recognition of English as a lingua franca (ELF), a large number of studies have investigated the attitudes of learners towards different varieties of English as well as their related accents. However, this attitude towards L1 accented English within the context of Iran has not been explored yet. Thus, the present study ecologically investigated the attitudes of Iranian English as Foreign Language (EFL) learners towards their L1-accented English based on Bronfenbrenner's (1993) nested ecosystems model consisting of micro-, meso-, exo-, and macro- systems. To do this, a triangulation of data collection using an attitudinal questionnaire distributed among 157 respondents (118 female and 39 male) and semistructured interviews with 60 participants ( 38 female and 22 male) were collected. The findings indicated a dominant emerging pattern of preference for native-like accent within the ecology of Iran along with the acknowledgement of L1 accented English. Maintaining linguistic security and self-confidence as well as teachers' role and materials used within the microsystem of the class, learners' background experiences within the mesosystem, policies of English language institutes at the exosystem, and the public view towards accent at the macrosystem contributed to the emerging pattern of preference for native-like accent within the context of Iran.
\end{abstract}

\section{Introduction}

In his work "English as an international language: perspectives and pedagogical issues", Sharifian (2009) highlighted the increasing interest in the emergence of English as an international language (EIL) in recent decades. EIL refers to English language as a new means of communication as a common language across different nationalities and cultures due to a range of reasons, especially educational, economic and socio-political 
ones. Other terms have also indicated the same concept such as global English, world Englishes (WEs) (Kachru, 1990) or English as a lingua franca (ELF) (Seidlhofer, 2005) by referring to the internationality of English. It has been reported that "up to 80 percent of communication in English is between non-native speakers" (Timmis 2002: 48). One of the models which supports the traditionally accepted foundation of EIL is Kachru's (1996) Circles. Inner Circle refers to 'native speaker' sites of English such as America. The outer Circle refers to countries in which people learn and use English as second language (ESL), such as India. The expanding circle refers to those who learn and use English as a foreign language (EFL), such as Iran, the focus of this research. However, it should be noted that native-or non-native-like English speakers' communication is not limited to the borders of the countries. That is, in Iran, some English learners prefer to speak like a native speaker while some others maintain their own Iranian, non-native English.

One of the main concerns underlying these common concepts is the localization of English language used in different parts of the world. As English has spread globally, World Englishes has been recognized widely; thus, a large number of studies have been carried out to explore learners' attitudes towards existing varieties of English (e.g. Friedrich 2000; Kirkpatrick \& Xu 2002; Matsuda 2002; Tokumoto \& Shibata 2011). Despite the considerable body of studies conducted in the field (e.g., Giles and Billings 2004; Garrett 2010), there exists a lack of a widely agreed definition of language attitudes. In general, two ontological positions, language attitudes as either stable or variable evaluative phenomena, can be explored in the literature. As a stable construct, it can be "identified with a reservoir of stable (but not enduring) evaluative dispositional concepts, directed to a linguistic phenomenon, and underlying observable responses which are constructed situationally" (Ishikawa and Morán Panero 2016:79). To investigate attitude in its stable sense, several methods have been used, for instance, societal treatment, matched guise technique (MGT), verbal guise technique (VGT), to name a few. However, they do not accord with the nature of ELF. For example, societal treatment might not be regarded as equal with individuals' attitudes because it is 
stereotypically pivoted on the premise that a sample research is the representation of a given speech community (e.g., Jenkins 2007; Ishikawa 2016a). In addition, MGT and VGT do not seem to be consistent with ELF research which "targets, and seeks to comprehend in situ, English communication across geographical boundaries" (Ishikawa 2016b: 129) and in line with ELF communication as "dynamic, pluralistic manifestations of linguistic resources in an international setting" (Ishikawa 2015: 39). Furthermore, the underpinning assumptions of MGT and VGT contradict the principles of social meaningmaking by considering a pre-defined, a-contextual, fixed and direct link between linguistics features and social meanings (Ishikawa and Morán Panero 2016). Moreover, some researchers have used direct approaches like interviews and questionnaire, but regarding the limitations of these instruments, it should be mentioned that the scope of enquiry might be confined to predetermined evaluation categories by the close-response items which might not reveal lingua franca communication with its complexity (Mauranen 2012; Mortensen 2013; Baird et al. 2014).

In its variable sense, attitudes can be defined as "variable and emergent forms of evaluative social practice around a language-related issue" (Ishikawa and Morán Panero, 2016:74). This is consistent with "the importance of viewing language from multiple dimensions in which its contextual embodiment is crucial" (Baird et al. 2014: 181, 190). Wiggins and Potter (2003) criticized the stable sense in investigating attitudes as "underlying mental constructs behind evaluations" (ibid: 513 ) by pointing out that researchers in the field mainly neglected to examine the variable construction of evaluations in performing specific contextual social actions by assuming that evaluations function "primarily as referents of internal states" (ibid: 514). Attitude is then regarded as variable rather than static because it is under constant negotiation and construction via individuals' interactions (Potter 1998; Puchta and Potter 2004; Ishikawa and Morán Panero, 2016). That is, language attitudes are interactionally created and socially developed and, thus, their nature is "explained in terms of emergence" (Ishikawa and Morán Panero, 2016: 87). In Potter's (1996: 139) terms, understanding the reason for an individual's specific opinion requires understanding the "social and [contextual] 
representation of the object being considered" (Ishikawa and Morán Panero 2016: 87). In fact, scholars are required "to understand the social representation of an evaluated object as it is constructed by a speaker in a particular point in time, and be prepared to examine its potential variability" (Ishikawa and Morán Panero 2016: 91).

With multiple conceptualisations and evaluations being available to the same person, establishing which of these responses, sometimes conflictive, can contribute to a stable evaluative predisposition is not the aim but "the goal is to understand why a particular evaluation is formulated in a particular context" ( Ishikawa and Morán Panero 2016:92). Attitudinal research within the domain of speaker evaluation has contributed to establishing a strong association between language use, as well as perceived ways of speaking, with social meanings (Coupland, 2007). In this study, which considers an attitude as an "interactionally co-created and variable social practice" (Ishikawa and Morán Panero 2016: 90), we aimed to explore the emerging attitudinal patterns of Iranian English learners regarding their accents in English as rooted in, and explained by, different contextual layers named ecosystems by "going beyond measuring" and simply "quantifying positive or negative attitudes" (Ishikawa and Morán Panero 2016: 90). Indeed, we aimed to pay serious attention to the social representation through which the participants construct their attitudes towards their accent in English, as why "the representations and resulting evaluations fluctuate" (Ishikawa and Morán Panero 2016: 91).

Table 1 illustrates the attitudes of learners according to research from different parts of the world towards English language. The findings of these studies mainly indicate the diversity of attitudes towards the varieties of English in different parts of the world.

\section{Table 1.}

A summary of some studies on attitudes of learners in different parts of the world towards English language 
Study

Flaitz's (1993) investigation of French learners' perceptions of the relationship between the English language used as a lingua franca and American culture and ideology.
Method

Mixed- method

\section{Result}

The major results based on the respondents' opinion were: 1 . English is widespread in France. 2. French attitudes toward the English language, the native speakers of English, and the culture which they represent are positive. 3. Attitudes of the general public, as manifested in the responses of the subjects, diverge clearly from those of the French power elite.

\begin{tabular}{lll}
\hline Starks and Paltridge's (1996) & Questionnaire & The results showed that the learners \\
examination of the attitude of & & mainly preferred a combination of \\
Japanese learners of English in & American and British English.
\end{tabular}

New Zealand, using a new technique called apparent time, towards different varieties of

English.
Crismore, Ngeow, and Soo's (1996)

study on attitudes toward English in Malaysia.

Questionnaire

Tokumoto and Shibata's (2011) study on Asian varieties of English:

Attitudes towards pronunciation.

\begin{abstract}
The findings showed that the Malaysian speakers of English considered Malaysian English functional but they are still eager to learn Standard English because they regard Malaysian English as 'wrong' English.

The results of the survey revealed that the Malaysian students highly valued their accented English, while the Japanese and Koreans disapproved of their own varieties of English and indicated their preference for native English Pronunciation.
\end{abstract}

\footnotetext{
Wiebesiek, Rudwick, and Zeller's (2011) study on South African Indian English: A qualitative study of attitudes.
}

Interview

The results showed that young South African Indian students who participated in the study had a profoundly ambiguous attitude towards the variety associated with their own ethno-linguistic group.

Nejjari, Gerritsen, Haagen, and
Korzilius's $\quad(2012)$ study on
Responses to Dutch-accented
English.

Interview

By comparing the attitudes toward British English pronunciation and Dutch English accents, the results showed that British English pronunciation was highly preferred and evoked more status than both Dutch English accents.

\begin{tabular}{|c|c|c|}
\hline $\begin{array}{l}\text { Bernaisch's (2012) study on } \\
\text { attitudes towards Englishes in Sri } \\
\text { Lanka. }\end{array}$ & Questionnaire & $\begin{array}{l}\text { The findings of the survey indicated } \\
\text { that British English is greatly valued } \\
\text { in Sri Lanka and it also showed that } \\
\text { Sri Lanka English is a variety of } \\
\text { English and the participants } \\
\text { expressed a positive attitude toward } \\
\text { it. }\end{array}$ \\
\hline
\end{tabular}


Bernaisch's and Koch's (2016) study on attitudes towards Englishes in India.
Questionnaire

The results showed that Indian speakers of English, especially the group of young females, displayed a positive attitude towards Indian English but the informants viewed British English in a more favorable light.

One reason for the diversity of the findings of these studies might be that attitudes, in their dynamic and variable sense, can be constructed under the influence of external influences (Bohner and W"anke 2002). One of these external factors impacting upon learning a language is the social environment. Particular attitudes towards the English language might emerge in our social environment by hearing others referring to the language and culture of some given groups and people in a certain manner, or via exposure to instructions reflecting teachers' pedagogical beliefs and choices regarding particular varieties of English. As a consequence, this leads to stereotyping English and its native speakers (McKenzie 2008) on the part of learners influencing their behaviors in the process of learning English, in such areas as their motivation, achievement as well as their classroom practices. In this sense, it is pedagogically important to uncover the attitudes of learners of English towards English language. To do this, an ecological perspective can contribute to the examination of the attitudes of students because this approach targets emerging patterns within the classroom ecology by exploring the relationship between language learners and all their related affective, cognitive, and linguistic variables (Mercer 2012; Van Lier 2004) which is not possible without considering the contexts in which they are embedded (Larsen-Freeman 2016).

Thus, ecological exploration of Iranian EFL learners towards English language in terms of their interconnection with their surrounding environment can provide us with new insights into exploring the agents contributing to the emergence of their attitudes towards their accent in English language. One of the most appropriate ecological models is Bronfenbrenner's $(1979 ; 1993)$ nested ecosystems model. The rationale for the use of this model in this study was its emphasis on the mentioned ecological features (Van Lier 2004). This model explores human development and behavior within and across a 
set of nested and interdependent structures called ecosystems. Four layers exist within these structures, namely the micro-, meso-, exo-, and macro-systems, ranging from the immediate setting to the overall social and cultural context. The microsystem exists as the innermost layer, referring to "a pattern of activities, roles, and interpersonal relations experienced by the developing person in a given face-to-face setting" (Bronfenbrenner 1993: 15).

\section{Theoretical framework}

The notion of world Englishes, EIL, ELF and Bronfenbrenner's (1993) nested ecosystem model are used as the theoretical framework of this study. Although debates over the conceptualization and scope of World Englishes has met with resistance and spawned other fields with different agenda, we use World English in a more general sense of a research interest in Englishes within Katchru's circles that are characterized by regional, cultural and usage-based differences, which can include social influences and attitudes. In this way, similar labels can be complementary to the term World Englishes in its general sense such as English as an international language, international Englishes, localized varieties of English, non-native varieties of English, second language varieties of English, world Englishes, new Englishes, global Englishes, new varieties of English and English as lingua franca. However, it should be stressed that there are still some controversies over their belonging to the same field.

In a narrower scope, the label World Englishes implies the "new Englishes" detected in the Caribbean and in West African and East African communities including Nigeria and Kenya as well as to Englishes in Asia such as Philippine English, Indian English, Malaysian English, Hong Kong English, and Singaporean English. In general, studies of this type mainly address the local features of Englishes in a given nation or region, emphasizing the linguistic description of varieties of Englishes. In a narrower sense, world Englishes indicates the study of the English language around the world in particular association with "world Englishes paradigm" developed by Kachru (1990), characterized by an underlying assumption arguing for the significance of pluricentricity in orientations and methods to the linguistics of English language used worldwide. Not 
only does it include the description of national and local varieties of English, but also it involves a plethora of other relevant topics such as creative writing, critical linguistics, contact linguistics, discourse analysis, corpus linguistics, lexicography, pidgin and creole studies, pedagogy, and the sociology of language (Bolton 2002).

EIL refers to a relatively new mode of communication across different cultures or nationalities via a common language. Undoubtedly, EIL, ELF and world Englishes (see Jenkins 2015; Melchers and Shaw 2003) are associated with the phenomenon of globalization, which is often pushed to the periphery within the traditional English language teaching (ELT) context dominated by the standards set by native-speakers. EIL, along with ELF in particular (House 1999; Jenkins 2015; Seidlhofer 2001), has challenged the ELT profession by indicating that non- native speakers can be as influential as native speakers in the shaping of English language (Seidlhofer 2005). Within the growing research on ELF (e.g. Baird et al. 2014; Baker and Jenkins, 2015; Baker et al. 2015; Jenkins 2015; Seidlhofer 2015), the emerging orientations of nonnative speakers towards ELF and their related underlying factors is yet to be investigated among which accent can be the most tangible one. Thus, the attitudes of non-native speakers of English towards the accent they use in English can be explored via the micro and macro contextual considerations.

Ecological research with its emphasis on research in context, or situated research, encompasses a number of consequences. Consistent with the contextual requirements, a major consequence is that any research is seen as a piece of the ecological puzzle (Bronfenbrenner 1993). The educational context can be characterized as a set of nested ecosystems, each one resting inside the next (Bronfenbrenner 1979; 1993), with each system having its own set of agents and artifacts, and its own operational emerging patterns. In addition, each ecosystem functions on its own cycles of events and time scales. According to Bronfenbrenner (1993), the ecosystemic hierarchy can be constructed by microsystem, mesosystem, exosystem, and macrosystem. The microsystem is the innermost layer covering "a pattern of activities, roles, and interpersonal relations experienced by the developing person in a given face-to-face 
setting" (Bronfenbrenner 1993, P. 15). The mesosystem explores the interconnection between two or more settings containing the developing person. Past learning experiences and extracurricular activities are examples within the mesosystem. The exosystem involves linkages between two or more settings in which at least one of them does not contain the person but has influence on his/her behavior in the immediate setting. The macrosystem encompasses social, educational, and cultural factors influencing the microsystem. Thus, the attitudes of Iranian learners of English as nonnative speakers of English can be explored in terms of the ecosystemic interaction of factors at micro-, meso-exo-and macro system.

Considering the above concern, this study investigates the attitudes of Iranian English learners towards their accent in English language from an ecological perspective. In other words, this study explores the ecosystemic influences such as gender, education level, starting age for learning English, the role of teachers, the role of family and friends, materials, environment, media, and society, which influence the emerging patterns of their attitudes.

Research questions:

(1) What are the attitudes of Iranian English learning university students towards their L1-accented English?

(2) Are there significant differences between Iranian male and female English learners' attitudes toward L1 accented English?

(3) Is there any significant relationship between learner's age and their attitudes toward L1 accented English?

\section{Method}

\section{Participants}

This study used an accessible sampling method in which a certain group of Iranian learners of English were chosen for the purposes of the study. For the quantitative part, 157 participants of both genders (118 female and 39 male) were recruited from two 
universities in Iran, the University of Bojnord and Imam Reza International University of Mashhad, as well as two private institutes. The field of study for 90 participants was English (translation, teaching and literature) but the rest were majoring in science, engineering, business, and law. The participants were from different years in college. Their age ranged from 14 to 50 and they had different levels of English (Beginner, Intermediate and advanced). Among these, 60 participants (38 female and 22 male) took part in the interview sessions. All of the participants' first language was Persian.

Table 2.

Participants' demographic characteristics, frequency, and percentage

\begin{tabular}{|c|c|c|}
\hline Den & mographic characteristics & Frequency/percentage \\
\hline \multicolumn{3}{|l|}{ Gender } \\
\hline & - $\quad$ Female & $118 / 75 \%$ \\
\hline & - Male & $39 / 24 \%$ \\
\hline \multicolumn{3}{|l|}{ Level } \\
\hline & - $\quad$ Beginner & $2 / 1 \%$ \\
\hline & - Intermediate & $63 / 40 \%$ \\
\hline & - $\quad$ Advanced & $92 / 58 \%$ \\
\hline \multicolumn{3}{|l|}{ Age } \\
\hline & - $\quad 14-22$ & $103 / 65 \%$ \\
\hline & - $\quad 23-27$ & $41 / 24 \%$ \\
\hline & - $28-32$ & $9 / 5 \%$ \\
\hline & - $\quad 33-42$ & $2 / 1 \%$ \\
\hline & - $\quad 38-50$ & $2 / 1 . \%$ \\
\hline
\end{tabular}

We conducted the interviews at the location considered for data collection. Having collected the questionnaire data, we provided further information regarding the interview purposes and process. We asked the survey participants to inform us about their voluntary participation in the follow-up interviews. We planned to interview 60 students who were selected based on their demographic diversity, elicited from the 
information provided through the questionnaires. This approach allowed the recruitment of interviewees with different backgrounds in order to provide a more comprehensive understanding of the different ecological factors contributing to their patterns of attitudes towards their Persian English accent.

\section{Instruments}

The Persian translation of the questionnaire developed by Tokumoto and Shibata (2011) was used in this study (see Appendix). Its reliability turned out to be high with .90 Cronbach alpha. It included 12 Likert-type items. We asked the participants to rate each statement by their level of agreement: $6=$ strongly agree, $5=$ agree, $4=$ moderately agree, $3=$ moderately disagree, $2=$ disagree, $1=$ strongly disagree. The items in this scale measures attitudes of the participants within 5 aspects of accentedness, intelligibility, acceptability, affect and behavior.

Out of the 12 statements, items $3,6,7,10,11$, and 12 , which are categorized as the cognitive aspect, were further divided into three subcategories: accentedness (item 3), intelligibility (items 6 and 7), and acceptability (items 10,11, and 12). Participants were asked to judge whether they were affectively attached to their own English pronunciation in items 1 and 4. The participants' behavioral intentions in relation to speaking English were attemptedly uncovered through items 2, 5, 8, and 9.

The interviews were semi-structured. The purpose of interviews was to elicit data to complement, refine, and contextualize the results from the survey, so we developed the interview questions in accordance with the questionnaire themes. The interviews were conducted in a casual and natural style rather than a formal pattern of asking and answering. We audio-recorded all the interviews with signed permission from interviewees and were conducted in the participants' L1, Persian.

Despite the limitations of investigating explicit evaluation via direct closed forms, "Semi-structured interviews allow participants to introduce, draw upon, redefine or even reject linguistic notions, ideas and experiences in their own ways during the formulation of situated evaluation" (Ishikawa and Morán Panero, 2016:91). Furthermore, semi- 
structured interviews "allow space for variable conceptualisations and evaluations of the same linguistic phenomenon to emerge in the same interaction" (Ishikawa and Morán Panero 2016:91). Some researchers have questioned the explanatory nature of the evaluative data they produce (e.g., Park 2009; Potter 2012). That is, attitudinal findings elicited via interviews might not provide direct insights into individuals' evaluative practices in 'non-elicited' interactions (Ishikawa and Morán Panero 2016). Despite these limitations, direct methods of enquiry like semi-structured interviews are "still highly useful to identify at least a partial set of various interpretative and evaluative repertoires in relation to participants' reported experiences (e.g., Hsu and Roth 2012)" (Ishikawa and Morán Panero 2016:92) and "to explore the potential variability of evaluative practices in ELF studies" (Ishikawa and Morán Panero, 2016: 93). Furthermore, refuting the validity of direct methods "on the grounds that elicited data is less 'real', 'natural' or 'valid' than non-elicited interactions" (Ishikawa and Morán Panero, 2016:93) is not possible. Since interactions in direct methods may be understood as social practices in their own right (e.g., Mann 2011; Talmy 2010), it can only be claimed that using each method might result in a different type of data, "with a different explanatory scope" (Ishikawa and Morán Panero, 2016: 93)

\section{Data collection}

Data collection for this study lasted approximately two months. After selecting the universities and institutions, some classes and groups were selected. The questionnaire was distributed to accessible students during the last 20 minutes of class session. Before starting to answer the items, the participants were given an opportunity to answer the demographic items. The instructions were provided on top of the page. Participants were informed that their participation was voluntary. They also were informed that their responses would be kept strictly confidential.

First, the questionnaires were distributed among the participants and the instructions were explained. Answering the questionnaire took about 20 minutes in each session. Then, the questionnaires were collected. Second, after collecting the questionnaires, the 
volunteer participants took part in the interview. The participants were interviewed one by one on a time-planned schedule. Collection of all these quantitative and qualitative data took near 7 sessions during 1 month.

\section{Data analysis}

SPSS (version 21) was used for quantitative data analysis part of this study. Included in the analysis were percentages and frequencies, as well as central tendency (mean, median, and mode) and variability measures (range and standard deviations). Due to the ordinal nature of Likert-type items, for each item in the first domain, the most frequently selected scale was identified using the mode. Items' summated scale for each respondent was interval, so, in this domain, a mean was calculated for each respondent along with the mean of all the respondents. In addition, to allow all the interviewees to express their opinions freely, all the interviews were conducted in Persian. Content analysis was conducted for the analysis and interpretation of the interview data. We identified common and recurring patterns and these were investigated independently of the questionnaire data. The interview data were qualitatively analyzed via grounded theory (Strauss and Corbin 1998) encompassing open coding, axial coding, and selective coding to uncover the ecosystemic factors based on Bronfenbrenner's model. Using MAXQDA software program, we coded and classified the participants' expressions and ideas in order to figure out what elements would affect their attitudes towards accent of English language. For example, classroom environment and teacher's factors were classified within microsystem of the class.

\section{Results}

Table 3, below, indicates the quantitative analysis of the collected data.

\section{Table 3.}

Descriptive statistics, attitudes toward L1 accented-English 


\begin{tabular}{|c|c|c|c|c|c|c|c|c|}
\hline \multirow{2}{*}{$\begin{array}{l}\text { Statement } \\
\text { f / \% }\end{array}$} & & & & & & & \multirow[b]{2}{*}{ MD } & \multirow[b]{2}{*}{ MO } \\
\hline & $\mathrm{SD}$ & $\mathrm{D}$ & $\mathrm{MD}$ & MA & $\mathrm{A}$ & SA & & \\
\hline \multirow[t]{2}{*}{ (1) I am confident in my English pronunciation. } & 2 & 4 & 25 & 55 & 57 & 14 & 4 & 5 \\
\hline & 1.3 & 2.5 & 15.9 & 35 & 36 & 8.9 & & \\
\hline \multirow[t]{2}{*}{ (2) I speak English with a native-like accent. } & 5 & 20 & 39 & 61 & 23 & 9 & 4 & 4 \\
\hline & 3.2 & 12.7 & 24.8 & 38.9 & 14.6 & 5.7 & & \\
\hline \multirow[t]{2}{*}{ (3) I have a non-native accent. } & 9 & 18 & 35 & 50 & 39 & 6 & 4 & 4 \\
\hline & 5.7 & 11.5 & 22.3 & 31.8 & 24.8 & 3.8 & & \\
\hline \multirow[t]{2}{*}{ (4) I am happy with my accent. } & 7 & 20 & 25 & 37 & 52 & 16 & 4 & 5 \\
\hline & 4.5 & 12.7 & 15.9 & 23.6 & 33.1 & 10.2 & & \\
\hline \multirow[t]{2}{*}{ (5) I hesitate to show my accent. } & 22 & 35 & 35 & 42 & 18 & 5 & 3 & 4 \\
\hline & 14.0 & 23.3 & 23.3 & 26.8 & 11.5 & 3.2 & & \\
\hline \multirow{2}{*}{$\begin{array}{l}\text { (6) Native speakers can easily understand my accented } \\
\text { English }\end{array}$} & 9 & 10 & 21 & 47 & 52 & 18 & 4 & 5 \\
\hline & 5.7 & 6.4 & 13.4 & 29.9 & 33.1 & 11.5 & & \\
\hline \multirow{2}{*}{$\begin{array}{l}\text { (7) Non-native speakers can easily understand my } \\
\text { accented English. }\end{array}$} & 7 & 11 & 24 & 46 & 50 & 19 & 4 & 5 \\
\hline & 4.5 & 7.0 & 15.3 & 29.3 & 31.8 & 12.1 & & \\
\hline \multirow[t]{2}{*}{ (8) I would like to keep my accent. } & 13 & 27 & 26 & 33 & 43 & 15 & 4 & 5 \\
\hline & 8.3 & 17.2 & 16.6 & 21.0 & 27.4 & 9.6 & & \\
\hline \multirow{2}{*}{$\begin{array}{l}\text { (9) I would like to sound like a native speaker of } \\
\text { English. }\end{array}$} & 6 & 3 & 11 & 15 & 33 & 89 & 6 & 6 \\
\hline & 3.8 & 1.9 & 7.0 & 9.6 & 21.0 & 56.7 & & \\
\hline \multirow{2}{*}{$\begin{array}{l}\text { (10) My pronunciation would be acceptable in } \\
\text { international business. }\end{array}$} & 2 & 15 & 52 & 54 & 27 & 7 & 4 & 4 \\
\hline & 1.3 & 9.6 & 33.1 & 34.4 & 17.2 & 4.5 & & \\
\hline \multirow{2}{*}{$\begin{array}{l}\text { (11) My pronunciation would be acceptable for an } \\
\text { English teacher. }\end{array}$} & 3 & 8 & 26 & 63 & 43 & 14 & 4 & 4 \\
\hline & 1.9 & 5.1 & 16.6 & 40.1 & 27.4 & 8.9 & & \\
\hline \multirow{2}{*}{$\begin{array}{l}\text { (12) My pronunciation would be acceptable in personal } \\
\text { cross-cultural communication. }\end{array}$} & 1 & 5 & 33 & 65 & 38 & 15 & 4 & 4 \\
\hline & 0.6 & 3.2 & 21 & 41.4 & 24.2 & 9.6 & & \\
\hline
\end{tabular}

\footnotetext{
*Strongly Disagree = SD, Disagree = D, Moderately Disagree = MD, Moderately Agree = MA, Agree = A, Strongly Agree $=\mathrm{SA}$, Median $=\mathrm{MD}$, Mode $=\mathrm{MO} ;$ frequency $=\mathrm{f}$, percentage $=\%$
}

The analysis of the findings from the questionnaire indicated that most of the respondents recognized the status of English as an international language and they were eager to speak it with a native accent. This claim is evident from the following observations: $85 \%$ of the participants agreed with the statement "I would like to sound like a native speaker of English" (\#9) which might indicate an inclination towards nativelike accent. In addition, the analysis of item 3 reveals that $60 \%$ of the participants consider their accent a non-native accent. However, around $60 \%$ of the participants 
agreed with the statement "I speak English with a native-like accent" (\#2) and only $40 \%$ of them disagreed with this statement. This shows that while $60 \%$ of the participants acknowledge that they have a non native accent, the same percentage of participants is eager to sound like a native speaker in their speaking.

Furthermore, regardless of the majority of the respondents' preferences to sound like a native speaker, they do not hesitate to show their accented English. As seen in table $10,60 \%$ of the participants disagreed with the statement "I hesitate to show my accent" (\#5). Likewise, more than half of the participants prefer to maintain their accent as $58 \%$ of the participants agreed with the statement "I would like to keep my accent" (\#8) which supports the previous finding.

The follow-up interview analysis provided possible reasons for what appeared to be inconsistent responses from participants in the likert-scale items. Mixed attitudes toward the variety of English may be a factor in such inconsistency. Some students state a preference for native-like English pronunciation due to its perceived international recognition and intelligibility, while others do not consider non-native English speakers achieving native-like pronunciation to be a realistic goal. Some also consider it understandable that Iranian students maintain a non-native accent when speaking English because it is not their first language. This is discussed in further depth in the interview findings.

As mentioned before, items (2), (5), (8), and (9) address the behavioral domain. Thus, all the findings of this part reveal that the majority of participants have positive attitude towards native accent and prefer to sound like a native speaker; however, with regard to their accented English, the participants reported two orientations. Some might contend that despite their preference to sound like a native, they were not unhappy with their accented English. By contrast, some others might hesitate to show their accented English. The result also shows that $80 \%$ of the respondents agreed with the statement "I am confident in my English pronunciation" (\#1) and 66\% of them agreed with item (4) which is "I am happy with my accent". 
In addition, the comprehensibility of their accented English might be confirmed by the observation that $75 \%$ of the participants agreed with the statement "native speakers of English can easily understand my accented English" (\#6) and about 70\% of them agree with item (7) which is "non-native speakers of English can easily understand my accented English". It is also interesting that they seem more comprehensible for native speakers than non-native speakers. Also, the acceptability of their accent might be confirmed by looking at the percentages of item (10) to (12). $55 \%$ of the respondents agreed with the item "my pronunciation would be acceptable in international business" (\#10); almost $75 \%$ of the participants agreed with the statement "my pronunciation would be acceptable for an English teacher" (\#11); and 75\% of them agreed with the statement "my pronunciation would be acceptable in personal cross-cultural communication" (\#12).

\section{Interview findings}

In the section below, findings are presented at four levels with reference to Bronfenbrenner's (1993) four ecosystems of microsystem, mesosystem, exosystem, and macrosystem.

At the microsystemic level, 5 themes, discovered in the final stage of grounded theory which is selective coding, were identified as influencing the attitudes of the participants towards native accent and L1 accented-English. These themes are classroom environment, teacher, tasks, affective factors, and cognitive factors.

\section{At the microsystemic level}

\section{Affective and cognitive factors}

Anxiety was one major affective factor impacting upon the participants' attitude towards their own L1 accented-English on a negative way (Yu 2010). For learners, this seems to stem from concerns about both the teachers' and classmates' attitudes towards their accent. One of the participants in answering to "are you confident in your English 
accent?" expressed that "I have a non-native accent and I always prefer to keep silent because I am afraid of being ridiculed by my classmates" (Interviewee 15). .

However, one major affective factor supporting some participants' preference towards a native like accent was to increase their self-confidence in interactions. This confidence was found to be due to the following reasons. Many of them reported that, to gain a high level of confidence in classroom conversations, they tried to acquire a native-like accent by watching American movies" (Interviewee 4, 34, and 60). Likewise, another participant regarded the switch to a native-like accent as a justification for raising his confidence in the class. "I feel highly confident when I take a native-like accent because this way I can draw the attention of my classmates, even my teacher, to myself" (Interviewee 24). In addition, for some participants, this switch to a native-like accent was accompanied with a sense of superiority to the other students in the class. "Having a native like, American, accent, I feel superior to my classmates" (Interviewee 14). In a similar vein, another one reported "Taking advantage of a native-like accent is followed by a sense of superiority to my classmate, I can cover my grammatical flaws and defects in conversations" (Interviewee 2). Some other participants considered the influence of native like accent on the audience as one of the reasons to value native like accent more than non-native accent. One of the participants said: "In my opinion, the beauty of accent definitely affects my audience, so I would like to have a native-like accent" (Interviewee 3). Also, another one said: "having a native like accent is more prestigious than a Persian English accent" (Interviewee 43).

Cognitive factors concerned students' beliefs and reasoning underlying their attitudes towards the accent they use in English. A common theme was for interviewees to maintain that their non-native English accent is comprehensible for both natives and non-natives due to the following reasons:

- It is comprehensible

- It is simple

- Correct pronunciation is more important than accent

- Having good communication does not depend on having native accent 
Some participants reported that they had no problems using their own Persian accent in the class because for them appropriate communication was more important than presenting a native-like accent. "We are learners of English as a foreign language; so naturally, we cannot acquire a native like accent. We'd better focus on the appropriate conveyance of our messages. So I feel confident with my nonnative accent communicating in English with my classmates inside the class and tourists visiting Iran" (Interviewee7). Another one said "I had the experience of talking to some tourists; my accent was clearly comprehensible for them" (Interviewee 39). Furthermore, this priority of appropriate communication over accent rendered these participants indifferent regarding the accent they use in their communication. As far as they could succeed in their communication using a comprehensible accent, accent was not considered a burden for them. Therefore, they preferred improving their knowledge of vocabulary and grammar to making their accent close to a native one. "Appropriate communication does not belong to a native or non-native like accent but correct pronunciation is the case" (Interviewee 54). To put it another way, they went beyond the issue of a preference for native/non-native accents to a preference for the correct pronunciation.

In a similar vein, some of the interviewees confirmed that their accented-English might be acceptable for their English teachers and personal communication as well as international communication for the following reasons:

- Having general English knowledge is more important than the accent in crosscultural communication

- Existence of English varieties with different accents.

- Larger number of non-native speakers than native speakers of English

- Little emphasis on accent on the part of some teachers in the class

- Having no problem in online virtual communication

Participants' perception about acceptability of their L1-accented English was investigated by asking "is your accent and pronunciation acceptable for international businesses, teachers, and personal cross-cultural communication?" Some of the participants maintained that since English language is an international language, there 
are varieties of English around the world and, thus, people speak English with different accents. Therefore, concentrating on one native like accent, they might feel incompetent communicating with these people. "English as an international language connects people with different languages, accents, cultures and nationalities. So, accent does not seem as important as the other dimensions like vocabulary, grammar, and pragmatics" (Interviewee 1). Another interviewee confirms the idea of acceptability of his L1-accented English in international commercial interactions. He mentioned that "in international business interactions, accent doesn't really matter; all businessmen express their messages having their own accent" (Interviewee 7, May 2016).

\section{Classroom environment}

Consistent with Yu's (2010) findings, within the microsystem of classroom ecology, classroom environment was reported to influence the participants' attitudes towards L1 accented-English as well as native like accent. The most prominent themes related to the environment of the class are classroom atmosphere, classmates' attitudes, teacher factors, and learning materials. Classroom atmosphere refers to mood, emotions, or climate sensed and shared by the class and classmates. Regarding this, one of the interviewees said "The atmosphere of the class has an impact on the students' attitude toward their own accent and native accent. My teachers and classmates confirm and adore my accent" (Interviewee 55). A majority of the participants referred to the fact that their classmates' affirmation of their accented English, mainly the native-like one, encourages them to think positively about their accent and acknowledge it in the class.

Teachers' styles and methods were reported as another factor shaping the attitudes of the participants. The participants were particularly inspired by their teacher's appreciation of their accent. "When the teacher adores my accent, I become more and more interested in keeping my accent" (Interviewee 6). They mentioned that one of the reasons which made them prefer to sound like a native is their teacher's attitude. Some participants were eager to have teachers with native-like English accent who care about their accent as well. "One of the reasons that I love my British accent is my teacher's British accent" (Interviewee 25). On the other hand, some participants mentioned that 
they had some teachers who did not care about their students' accent but they mainly checked them to have correct pronunciation.

Materials used in the class for learning English constituted another environmental factor. The participants mentioned that one of the reasons that they aimed to sound like native speakers was that all the materials around them presented a native like model of speaking. Their books, audios, movies, songs, and listening activities were based on American or British accents. "Our books, our teacher's accent, the media which we use for learning English address speaking with a native like accent" (Interviewee 47). Furthermore, majority of them expressed that they had no chance of being familiar with other varieties of English accents in the classroom materials. There were just a few students who were familiar with Chinese-English and Japanese English accents.

\section{At the mesosystemic level}

The data revealed the linkages between the classroom micro setting and other settings containing the participants in terms of their background experiences which suggested a mesosystem in this study. In fact, the students' past learning experience and extracurricular activities were found to be major influencing factors for their attitude toward their accented English. Some with the experience of travelling abroad mentioned that accent was really influencing in their interactions with the foreigners. "Once in Turkey, meeting an Italian, he appreciated my American-like accent, though he spoke English with his Italian accent" (Interviewee 13). On the other hand, some noticed that tourists in other countries do not necessarily speak English with a native like accent. "In Iran, I've seen my classmates trying to imitate a native like accent, but travelling to Malaysia, few tourists spoke English having a native-like accent" (Interviewee 9).

In addition, learners' background experiences in their previous courses both at university and institutes set the stage for their inclination towards native like English in the class. Many of them remembered the teachers in those classes mainly having a native like accent. "I have passed three semesters in learning English; I have seen how 
important having a native like accent is in the class for my classmates and teacher" (Interviewee 7).

\section{At the exosystemic level}

The linkages between the classroom setting and course evaluation, international exams, and attitudes of supervisors that arose in the data were perceived to constitute the exosystem. As most of the participants reported, their course schedule as well as their books and materials for learning English were based on native accent and, thus, this indirectly encouraged learners to follow a native like accent trend. This made them see native accent as an ideal and standard form and try to have such an accent. Course evaluation factors especially for the preparation of international exams were also found to affect the students' attitudes towards their accent for speaking in English. Most of the participants aimed to take part at international exams and gain some international English degrees or certificates such as TOEFL so concerned with their performance in the speaking section of these exams, they longed for a native or near-native accent. "Attending some mock tests of IELTS, I think I could not speak well because I think my Persian accented English was not acceptable" (Interviewee 21). Besides, participants whose major was English were more eager to have a native like accent because they maintained that in their future students would judge them by the accent they use in the class: "I am going to be an English teacher in future; I need to be a near native speaker of English because of my students attitudes towards me" (Interviewee 60) They reported that they had already evaluated their performance of their teachers by the English accent they spoke in the first session of the class, although they considered other aspects of their teaching in the following sessions. In addition, for both English major and non English major students, in the interview session of the institutes, especially with the supervisor, native like accent seems to be a key to success. "Once, in the placement test, I started my speech with an American accent of English despite my lacks in the grammar. This helped me keep the floor of speech while receiving both verbal and nonverbal feedbacks from the interviewer" (Interviewee 8). 


\section{At the macrosystemic level}

The social, educational and cultural factors which influence the attitudes of students were viewed within the macrosystem. Most of them highlighted the fact that when it comes to learning English, accent becomes an inseparable aspect. "When speaking with a native like accent out of the class, people might judge you as a proficient speaker of English because it is the most noticeable aspect of English language" said one of the participants" (Interviewee 54). Another student said "sometimes I speak English with my classmates on our way to the institute, people around us mainly judge us by our accent. If we switch to an exaggerated native like accent, they will certainly look up to us as literate in English let alone whether we have adequate skills in English language or not" (Interviewee 31). Therefore learners' employing a native-like English accent can make up for their' incapability in applying language skills in the presence of the laypeople.

\section{Discussion}

The findings of this study indicate that despite acknowledging their own accented English, Iranian English language learners are mainly oriented towards native like accents of English. From an ecological perspective, underlying factors influencing the emergence of this orientation are nested within different ecosystems. Within the microsystem, anxiety due to a linguistic insecurity within the ecology of the class renders learners inclined to a native like accent. Some of them are afraid of being misjudged by their teacher and classmates regarding their performance in the class. This means that for some of the learners of English in the context of Iran accent is regarded as the most noticeable aspect of English language which can place both the teacher and the other students at the status of judgment concerning their performance in classroom activities. As a consequence, this justifies the shift from L1 accented English to a native-like one in the class to reduce one's anxiety and feel secure and confident at the same time. In other words, applying a native like accent as a defensive strategy against misjudgments, learners earn self-confidence because, by this shift, they 
might cover their incompetence in the main skills of English language. Within this microsyemic security pattern of native-like accent, teachers play a pivotal role as well. Following their teachers as their role models, some Iranian learners try to acquire a native-like accent by watching series and movies because it is the native-like accent which is appreciated in the class. On the other hand, in some other cases, some learners valued their own accented English because their teachers themselves had no native-like accent and, hence, appreciated their learners' own accent while having correct pronunciation.

This dominant pattern of native-like accent might be rooted in the materials used in the class as a major microsystemic factor explaining the abovementioned factors such as the linguistic insecurity learners feel due to their L1 accented English, the effort to feel confident by taking a native-like accent, and the appreciation of a native-like accent by some teachers in the class. The materials used by the teachers mainly cover nativelike aspects and this long-term exposure to these types of materials can mean getting accustomed to listening to a native like accent into a habitus, in Bourdieu's (1984) terms shaping the habits and dispositions of the learners of English in Iran, in which a pattern of preference for native-like accent emerges. On the other hand, from an exosystemic perspective, the Iranian institutes' selection of commercial coursebooks developed by the inner circle countries and, from a macrosystemic view, a lack of being exposed to an adequate number of tourists or foreign visitors with different accents, along with the mesosystemic background experiences of learners, might strengthen the status of this habitus and, as a result, the pattern of preference for a native-like accent emerges.

From an exosystemic perspective, institutes for teaching English have mainly addressed international exams like TOEFL and IELTS as well as others like FCE, CAE, and CPE along with the preparatory materials for these exams as the target for their learners. Thus, it seems inevitable that under the washback influence of these policies, the orientation towards the native-like accent emerges within the microsystem of the class. 
Considering the participants' background experiences in their previous courses, we can understand how a repeated emphasis on the native like accent in the learners' background can also contribute to the consolidation of native-like accented pattern. Learners' inclination towards a native like accent has not necessarily taken place due to the present time situation in the classroom ecology. However, in shaping the habitus of native-like accent, their prior experiences, as seen in the interview results, were influential. On the other hand, as seen in previous interaction experiences of some participants meeting foreigners abroad, divergent attitudes towards accents of English might occur. Some might insist on their acquired native like accent due to their appreciation by the tourists but some others might go on with their own accented English as they see that many people abroad do not speak English with a native like accent.

However, within this dominant native-like accented pattern, regarding the comprehensibility of L1 accented English, some Iranian EFL learners consider their accent adequately comprehensible within the broad community of practice of English language. They maintain that comprehensibility of the language does not depend on the accent but on the correct pronunciation. Consistent with Kachru and Smith's (2008) definition of comprehensibility, we can infer that Persian accented English has not, in these students' experiences, noticeably hindered the recognition of words meanings and the speakers' intentions. But this comprehensibility has not paved the way for its establishment within both the classroom ecology and outside the class in the society due the underpinning factors mentioned earlier shaping the emerging pattern of nativelike accent as a habitus.

This overshadowing of L1 accented English by this habitus can also be explained from Kachru's concentric circles (1990) from a macro-perspective. Iran is located within the expanding circle countries. English language in Iran is not an institutional or formal language used widely in the society. The only major sources for learning English are the large number of English language teaching institutes all over the country. Thus, the aforementioned underlying factors within the microsystem of the classroom ecology that 
contribute to the emergence of a native-like accent orientation, such as the materials, teachers, or the classmates expecting other learners to follow a native like accent under the influence of exosystemic factors such as those within the policies of these institutes, can reverberate through the ecological macrosystem. Thus, unavoidably, accent becomes so noticeable that people in society can first judge learners' ability in English language outside of their class by their accents.

\section{Conclusion}

In this study, we explored the underlying ecological factors shaping the attitude of Iranian English language learners towards their accented English. The findings indicated that L1 accented English is regarded as acceptable by a majority of the participants of the study; however, the emerging pattern of native-like accent can be dominant among them. Factors for this emergence were found to lie within a nested interaction of ecosystems. Anxiety was aroused due to the linguistic insecurity within the microsystem of the class which rendered them susceptible to the teachers' and their classmates' judgments concerning their accent. Also, teachers and the materials used in the class were influential within the microsystem. But this microsytemic pattern has been strengthened under the influence of the exosystemic institutional policies like the use of preparatory materials for international exams, and echoed in the macrosystem where learners' competence in English language is mainly judged by their accent outside the class.

While we tried to gain a better understanding of social-meaning making and evaluative behaviour, a note of caution should be cast "against making generalisations about the evaluative dispositions that our participants may have, whether at the time of data collection or in future evaluative situations" (Ishikawa and Morán Panero, 2016: 93). According to Park (2009: 21), what individuals express regarding their beliefs is not necessarily a representation of "the entire range of their underlying beliefs about language". Thus, further research on attitudes towards accent in English can be conducted via longitudinal and ethnographic studies to explore how English language 
users' attitudes may be "constructed and modified from interaction to interaction" (Ishikawa and Morán Panero 2016: 92).

\section{References}

Baird, Robert, Will Baker \& Mariko Kitazawa. 2014. The complexity of ELF. Journal of English as a Lingua Franca 3(1). 171-196.

Baker, Will \& Jennifer Jenkins. 2015. Criticising ELF. Journal of English as a Lingua Franca 4(1). 191- 198.

Baker, Will, Jennifer Jenkins \& Robert Baird. 2015. ELF researchers take issue with 'English as a lingua franca: an immanent critique'. Applied Linguistics 36(1). 121123.

Bernaisch, Tobias. 2012. Attitudes towards Englishes in Sri Lanka. World Englishes 31(3), 279-291.

Bernaisch, Tobias \& Christopher Koch. 2016. Attitudes towards Englishes in India. World Englishes 35(1), 118-132.

Bohner, Gerd \& Michaela W"anke, M. (2002). Attitudes and Attitude Change. Hove: Psychology Press.

Bolton, Kingsley . 2002. Chinese English: from Canton jargon to global English. World Englishes 21 (2), 181199.

Bourdieu, Pierre. 1984. Distinction: A social critique of the judgement of taste. Cambridge, MA: Harvard University Press

Bronfenbrenner, Urie. 1979. The Ecology of Human Development. Cambridge, MA: Harvard University Press.

Bronfenbrenner, Urie. 1993. The ecology of cognitive development: research models and fugitive findings. In: Wozniak, R.H., Fischer, K.W. (eds.). Development in Context: Acting and Thinking in Specific Environments (pp. 3-44). Hillsdale, NJ: Lawrence Erlbaum Associates.

Coupland, Nikolas. 2007. Style: Language variation and identity. Cambridge: Cambridge University Press.

Crismore, Avon, Karen Yeok-Hwa Ngeow \& Keng-soon Soo. 1996. Attitudes toward English in Malaysia. World Englishes, 15(3), 319-335.

Flaitz, Jeffra. 1993. French attitudes toward the ideology of English as an international language. World Englishes 12(2), 179-191. 
Friedrich, Patricia. 2000. English in Brazil: functions and attitudes. World Englishes 19 (2), 215-223.

Garrett, Peter. 2010. Attitudes to language. Cambridge: Cambridge University Press.

Giles, Howard \& Andrew C. Billings. 2004. Assessing language attitudes: Speaker evaluation studies. In Alan Davies \& Catherine Elder (eds.). The handbook of applied linguistics (pp. 187-209). Oxford: Blackwell.

House, Juliane .1999. Misunderstanding in intercultural communication: interactions in English as a lingua franca and the myth of mutualintelligibility'. In C. Gnutzmann (Ed.), Teaching and learning English as a global language: Native and non-native perspectives (pp.73-89). Tubingen: Stauffenburg Verlag.

Hsu, Pei-Ling \& Wolff-Michael Roth. 2012. Understanding beliefs, identity, conceptions, and motivations from a discursive psychology perspective. In Barry J. Fraser, Kenneth G. Tobin \& Campbell J. McRobbie (eds.), Second international handbook of science education, volume 2 (pp. 1435-1447). Dordrecht: Springer.

Ishikawa, Tomokazu. 2015. Academic rigour in criticising English as a Lingua Franca. Englishes in Practice 2(2). 39-48.

Ishikawa, Tomokazu. 2016a. A study of Japanese university students' attitudes towards their English. Southampton (UK): University of Southampton PhD thesis.

Ishikawa, Tomokazu. 2016b. World Englishes and English as a Lingua Franca: Conceptualising the legitimacy of Asian people's English. Asian Englishes 18(2). 129-140.

Ishikawa, Tomokazu \& Sonia Morán Panero. 2016. Exploring language attitudes in ELF research: Contrasting approaches in conversation. Englishes in Practice 3 (4). 74-109.

Jenkins, Jennifer. 2007. English as a Lingua Franca: Attitude and identity. Oxford: Oxford University Press.

Jenkins, Jennifer. 2015. Repositioning English and multilingualism in English as a Lingua Franca. Englishes in Practice 2(3). 49-85.

Kachru, Braj B. 1990. World Englishes and applied linguistics. World Englishes 9(1). 320.

Kachru, Braj B. 1996. World Englishes: Agony and ecstasy. Journal of Aesthetic Education, 30(2). 135-155

Kachru, Yamuna \& Larry E. Smith. 2008. Cultures, Contexts, and World Englishes. New York: Routledge.

Kirkpatrick, Andy \& Zhichang Xu. 2002. Chinese pragmatic norms and 'China English'. World Englishes, 21(2). 269-279.

Larsen-Freeman, Diane. (2016). Classroom-oriented research from a complex systems perspective. Studies in Second Language Learning and Teaching 6(3). 377-393. 
Mann, Steve. 2011. A critical review of qualitative interviews in applied linguistics. Applied Linguistics 32(1). 6-24.

Matsuda, Aya. 2002. International understanding through teaching world Englishes. World Englishes 21 (3). 436-440.

Mauranen, Anna. 2012. Exploring ELF: Academic English shaped by non-native speakers. Cambridge: Cambridge University Press.

Melchers, Gunnel \& Philip. Shaw. 2003. World Englishes. London: Arnold.

Mercer, Sarah. 2012. The complexity of learner agency. Apples - Journal of Applied Language Studies 6(2). 41-59.

Mortensen, Janus. 2013. Notes on English used as a lingua franca as an object of study. Journal of English as a Lingua Franca 2(1). 25-46.

Nejjari, Warda, Marinel Gerritsen, Monique Van der Haagen \& Hubert Korzilius,. 2012. Responses to Dutch- accented English. World Englishes31(2). 248267.

Park, Joseph Sung-Yul. 2009. The local construction of a global language: Ideologies of English in South Korea. Berlin: Mouton de Gruyter.

Potter, Jonathan. 1998. Discursive social psychology: From attitudes to evaluative practices. European Review of Social Psychology 9(1). 233-266.

Potter, Jonathan. 2012. Re-reading discourse and social psychology: Transforming social psychology. British Journal of Social Psychology 51(3). 436-455.

Puchta, Claudia \& Jonathan Potter. 2004. Focus group practice. London: Sage.

Seidlhofer, Barbara . 2001. Closing a conceptual gap: The case for a description of English as a lingua franca. International Journal of Applied Linguistics11(2). 133158.

Seidlhofer, Barbara. 2004. Research perspectives on teaching English as a lingua franca. Annual review of applied linguistics 24, 209-239.

Seidlhofer, Barbara. 2005. English as a lingua franca. ELT journal 59(4). 339

Sharifian, Farzad (Ed.). 2009. English as an international language: Perspectives and pedagogical issues (Vol. 11). Multilingual Matters.

Silverman, David. 2014. Interpreting qualitative data, 5th edn. London: Sage. Talmy, Steven. 2010. Qualitative interviews in applied linguistics: From research instrument to social practice. Annual Review of Applied Linguistics 30. 128-148.

Starks, Donna , \& Brian Paltridge, B. 1996. A note on using sociolinguistic methods to study non-native attitudes towards English. World Englishes. 15(2). 217-224.

Timmis, Ivor. 2002. Native speaker norms and International English: A classroom view. ELT journal. 56(3). 240-249. 
Tokumoto, Mina \& Miki Shibata, M. 2011. Asian varieties of English: Attitudes towards pronunciation. World Englishes 30(3). 392-408.

Van Lier, Leo. 2004. The Ecology and Semiotics of Language learning: A sociocultural perspective. New York: Kluwer Academic Publishers.

Wiebesiek, Lisa, Stephanie Rudwick \& Jochen Zeller. 2011. South African Indian English: A qualitative study of attitudes. World Englishes 30(2). 251-268.

Wiggins, Sally \& Jonathan Potter. 2003. Attitudes and evaluative practices: Category vs. item and subjective vs. objective constructions in everyday food assessments. British Journal of Social Psychology 42(4). 513-531.

Yu, Yang . (2010). Attitudes of learners toward English: A case of Chinese college students (Doctoral dissertation, The Ohio State University).

\section{APPENDIX \\ QUESTIONNAIRE}

Direction: on a scale of 6 , please rate yourself by crossing the number that best represents the corresponding statement applies to you

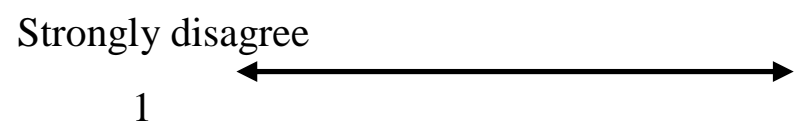

strongly agree

Items

(1) I am confident in my English pronunciation.

(2) I speak English with a preference for native-like accent.

(3) I have a non-native accent.

(4) I am happy with my accent.

(5) I hesitate to show my accent.

(6) Native speakers of English can easily understand my accented English.

(7) Non-native speakers of English can easily understand my Iranian accented English.

(8) I would like to keep my accent.

(9) I would like to sound like a native speaker of English.

(10)My pronunciation would be acceptable in international business.

(11)My pronunciation would be acceptable for an English teacher to approve of.

(12)My pronunciation would be acceptable in personal cross-cultural communication. 


\section{About the authors:}

Farzaneh Rajablou has an M.A. in Teaching English as a Foreign Language at Imam Reza International University, Iran. Her main interest is the ecology of foreign language learning and teaching.

Majid Elahi Shirvan is an assistant professor of Teaching English as a Foreign Language at University of Bojnord, Iran. His main interests are English as a global language and the ecology of foreign language learning and teaching. 